\title{
OS IMPACTOS DO RACISMO ESTRUTURAL NO ENSINO CONTÍNUO DA POPULAÇÃO NEGRA: UMA ANÁLISE DO NORTE DE MINAS GERAIS
}

\author{
Carlos Daniel Rodrigues de Oliveira \\ Graduado em Geografia Licenciatura Plena. \\ Universidade Estadual de Montes Claros - UNIMONTES. \\ E-mail: danielroliv82@gmail.com \\ Samuel Carlos Santos Marques \\ Graduando em Geografia Licenciatura Plena. \\ Universidade Estadual de Montes Claros - UNIMONTES. \\ E-mail: samuel35marques@gmail.com \\ Rahyan de Carvalho Alves \\ Doutor em Geografia pela Universidade Federal de Minas Gerais. \\ Professor na Universidade Estadual de Montes Claros - UNIMONTES. \\ E-mail: rahyan.alves@unimontes.br
}

\begin{abstract}
RESUMO
O racismo estrutural exposto como a manutenção de ações racistas cotidianas que tornam normais a inferioridade, agressões policiais, baixo índice educacional entre outras diversas mazelas sofridas pela população negra. Na América Latina essa condição parte do período da colonização, e foi sendo estruturada nas diversas mudanças de nossa estrutura política e social, levando a essa condição atual onde se torna banal a morte constante de crianças e adolescentes negros nas favelas brasileiras e sua baixa perspectiva de futuro educacional e profissional acentuando nossos índices de criminalidade. Buscou-se nesse artigo analisar o contexto teórico referente ao racismo estrutural e por meio dos dados do Instituto Brasileiro de Geografia e Estatística (IBGE), Instituto Nacional de Estudos e Pesquisas Educacionais (INEP), entre outros visando aprofundar uma discussão mais detalhada sobre a desigualdade racial, evasão escolar e abandono, dando origem a produção de tabelas e mapas que sustentam a teoria de desigualdade racial. Dados das organizações brasileiras corroboram com a hipótese de que a população negra, representa mais da metade dos alunos que abandonam os estudos nas séries iniciais e finais de ensino, por motivos relacionados à renda, falta de interesse na conclusão dos estudos e gravidez na adolescência, na perspectiva de analise onde correlacionamos esses fatores ao racismo estrutural, pontuamos que a teoria se confirma com esses dados quando notamos a normalização dessa condição desigual para a população negra tanto no viés do abandono escolar, quanto em questões relacionadas ao analfabetismo, violência e falta de representação política.
\end{abstract}

Palavras-Chave: Abandono. Racismo. IBGE. Norte de Minas.

\section{INTRODUÇÃO}

As marcas da colonização na América Latina, na atualidade, são vistas diante da instabilidade política e social que foram evidenciadas pelas manifestações sociais de apoio à democracia e contra o racismo. Além dos movimentos, em redes sociais, como o Vidas Negras Importam, que foi adaptado do movimento Black Lives Matter. Esse é um movimento ativista internacional, com origem na comunidade afroamericana, que luta contra a violência direcionada às pessoas negras. 
O caso que serviu de gatilho, para manifestações acaloradas nos Estados Unidos da América, foi o do americano George Floyd, que faleceu, em 25 de maio de 2020, por uma ação policial cruel onde foi sufocado até a morte em plena luz do dia, enquanto gritava por ajuda. Diante disso, é válido destacar que esses movimentos estavam em ativa desde 2013 diante de outro ocorrido que levou a morte de um americano negro ${ }^{1}$.

Se, por um lado, o fato descrito anteriormente serviu ao menos momentaneamente para os brasileiros enxergam o racismo como um problema ainda latente na sociedade, por outro lado, esse momento também evidenciou como não olhamos para o nossa própria realidade ao ter em vista que antes da morte de George Floyd, nos EUA, ações policiais, no Rio de Janeiro, no início de 2020 levaram a morte de: Ítalo Augusto, de 7 anos, que foi baleado enquanto brincava em casa, na baixada fluminense, além de Kauã Vitor da Silva, de 11 anos, morto no Complexo da Maré, e da Rayane Lopes, de 10 anos, assassinada durante uma festa junina no bairro Anchieta, dentre outros casos ${ }^{2}$.

Esses casos representam a materialização do Racismo Estrutural na sociedade brasileira, ressaltando a normalização da morte da população negra, e também vista em diversas outras situações de desigualdades raciais. Para contextualizar o conceito de Racismo Estrutural com nossa situação atual vamos transitar principalmente pelos anos de 1980 e 1990, período de extensa reforma constitucional em grande parte dos países da América Latina, como o Brasil com a Constituição, de 1988, Lei 7.716 de 1989, que previa punição para os crimes resultantes de discriminação ou preconceito de raça, cor, etnia, religião ou procedência nacional. Nesse sentido, a Colômbia com Constituição, de 1991 e Lei 70, de 1993, que previa programas de etano-educação nas escolas, representantes de comunidades negras em comitês e órgãos de tomada de decisão em vários níveis do estado (GUIMARÃES, 2006).

Destaca-se que essas mudanças ocorreram juntos a reconstrução do Estado democrático que se deu após décadas de autoritarismo que fizeram parte da história do continente - com ênfase entre 1960 a meados de 1980 -, essas reformas trouxeram novas discussões acerca do multiculturalismo e do multirracialismo, que apesar de

1 Disponível em: https://g1.globo.com/mundo/noticia/2020/05/27/caso-george-floyd-morte-de-homemnegro- $\quad$ filmado-com-policial-branco-com-joelhos-em-seu-pescoco-causa-indignacao-nos-eua.ghtml. Acesso em: 20 nov. de 2020.

${ }^{2}$ Disponível em: https://www.cnnbrasil.com.br/nacional/2020/07/04/historias-de-criancas-baleadas-norio-de- janeiro-ganham-destaque-em-protesto. Acesso em: 20 nov. de 2020. 
levar novos ideais e ideologias ainda se espelhava na Europa e nos Estados Unidos da América. Isso devido ao forte impacto da Globalização que se inseriu ainda mais com a queda dos regimes autoritários, que surgiram no período da segunda metade do século XX, que ficou marcada na história da América Latina pela grande quantidade de ditaduras militares implantadas em diferentes países da região, com destaque ao golpe civil-militar que ocorreu no Brasil em 1964 (GUIMARÃES, 2006; ROLLEMBERG e QUADRAT, 2010).

No Brasil ao fim da década de 1970, o Estado se viu forçado pelas lutas de democracia de grupos minoritários, principalmente de movimentos estudantis e grupos do movimento negro e indígena a garantir mudança de seus paradigmas sobre os ideais nacionalistas, em que a primeira ideia a ser rompida seria a homogeneização cultural e racial, por meio da instauração do multiculturalismo e multirracialismo junto a regulamentações dos direitos civis levando a igualdade formal e de oportunidades para os cidadãos de grupos distintos (GUIMARÃES, 2006).

As reformas constitucionais que levaram por exemplo a criação do Ministério da Cultura, em 1985, entre diversos outros exemplos que partiram dos preceitos de reconhecimento da diversidade cultural e étnica, visando a garantia de auxílio estatal educacional para os grupos minoritários e aos povos indígenas por meio de uma nova regulamentação jurídica acerca de propriedades coletivas e demarcações de terra com proteção legal. Esse cenário de mudanças de políticas públicas e renovação do pensamento sobre a diversidade humana, vieram da introdução de políticas neoliberais, no campo social e econômico ao dar espaço para a redemocratização e a reintegração das economias latino- americanas para acompanhar a nova economia mundial, a exemplo das políticas de integração regional e global, das parcerias e acordos bilaterais e multilaterais via Banco Internacional para Reconstrução e Desenvolvimento (BIRD), Fundo Monetário Internacional (FMI), União Europeia (U.E.), Mercado Comum do Sul (MERCOSUL), Bloco econômico em construção formado por Brasil, Rússia, Índia, China e África do Sul (BRICS), dentre outros (GUIMARÃES, 2006; SERRANO, 2016).

Porém, as reformas neoliberais de 1990 também ameaçaram a autonomia nacional das elites brasileiras, que diante de protestos e mobilizações étnicas que surgiram neste cenário de mudanças políticas, acabaram sendo obrigados a responder com direitos culturais e sociais aos grupos minoritários protestantes. As elites aproveitaram aquele 
momento para legitimar suas posições perdidas na mudança ocorrida com integração de ideais neoliberais que diminuía à força do Estado, que, por sua vez, foi construindo de forma menos evidente em um ambiente institucional que mantinha as desigualdades, mas que não deixava explícita essa ação cumprindo algumas demandas sociais daquelas mobilizações e estrategicamente estruturando o racismo que vivemos, na atualidade (GUIMARÃES, 2006).

Discutir a questão étnico racial brasileira, no âmbito da Ciência Geográfica, sempre foi e será uma tarefa árdua, no Brasil, porque a formação histórica e política do país baseia-se a fundo na cultura europeia que, por sua vez, nos moldou a pensar negativamente sobre como viver em sociedade com grupos plurais. Desse modo, ao se pensar em Geografia e cultura, temos o parecer da representatividade e visão de um próprio grupo sobre seu passado, como é exposto pelo músico e compositor, Leandro Roque de Oliveira, mais conhecido pelo nome artístico Emicida, na música Ismália, no álbum AmarElo (2019), com participação de Larissa Luz e Fernanda Montenegro, onde a história da loucura de Ismália - musa do poeta mineiro Alphonsus de Guimaraens (1870-1921) -, é comparada as experiências e vivências do negro, no Brasil.

O álbum da música é repleto de outras referências à cultura brasileira, e suas letras fortes e explícitas revelam, uma leitura agressiva de uma realidade negada, mas evidente de um grupo que sofreu e ainda sofre:

[...] Por que um corpo preto morto/ É tipo os hits das paradas/ Todo mundo vê mas essa porra não diz nada (...). Primeiro sequestra eles/ Rouba eles/ Mente sobre eles/ Nega o Deus deles/ Ofende/ Separa eles/ Se algum sonho ousar correr, cê pára ele/ E manda eles debater com a bala que vara eles [...] (EMICIDA, 2019).

Diante dessa realidade exposta pela música, o ápice do racismo estrutural é apresentado, onde a normalização da condição de pobreza e da violência contra a população negra chegou aos níveis extremos. Quando apresento a ideia de extremo não me refiro a falta de oportunidade de emprego, escravidão ou qualquer atitude discriminatória extremista, mas, sim, ao extremo da normalização. O Brasil apresenta, diariamente, em seus noticiários a população negra passando pelas mais diversas mazelas sociais, ao liderar o número de mortos por arma de fogo, comandando as porcentagens sobre aqueles que estão abaixo da linha da pobreza e sendo aqueles que ocupam majoritariamente os presídios brasileiros (IBGE, 2019). Mesmo assim, essa 
não é uma situação alarmante, não é uma questão comovente e por muito tempo não foi algo discutido nas academias.

A cultura da hierarquia de raças, da dominação dos mais fracos e da concepção de superioridade da cultura europeia enraizou ideologias centradas no privilégio de quem nasce branco - pensamento presente até a atualidade. Esse tema complexo e delicado, que perpassa os primórdios da história brasileira, é um elemento de extrema importância para entendermos a sociedade brasileira, após longos períodos de conflitos ideológicos e raciais. Assim, se cria uma falsa noção de democracia racial, ao negligenciar todo um passado de escravização, expropriação e violência contra as populações nativas, os africanos e seus descendentes afro-brasileiros.

Metodologicamente buscou-se analisar contexto teórico referente ao racismo estrutural e por meio dos dados do Instituto Brasileiro de Geografia e Estatística (IBGE), Instituto Nacional de Estudos e Pesquisas Educacionais (INEP) aprofundar em uma discussão mais densa sobre a desigualdade racial, evasão escolar e abandono.

Com relação a área de estudo, evolvendo todo o compilado de informações em um recorte espacial geográfico temos a mesorregião do Norte de Minas (TABELA 01), como sendo a delimitação da discussão sobre a evasão escolar.

Tabela 01: Distribuição por Cor e Raça nas Mesorregiões de Minas Gerais - 2010.

\begin{tabular}{|c|c|c|c|c|c|c|}
\hline Mesorregiões & Total & Branca & Preta & Amarela & Parda & Indígena \\
\hline $\begin{array}{l}\text { Metropolitana de Belo } \\
\text { Horizonte (MG) }\end{array}$ & 6.236 .117 & 2.412 .080 & 678.465 & 73.305 & 3.061 .295 & 8.934 \\
\hline $\begin{array}{l}\text { Sul/Sudoeste de Minas } \\
\text { (MG) }\end{array}$ & 2.438 .611 & 1.685 .535 & 143.872 & 11.904 & 595.309 & 1.990 \\
\hline Zona da Mata (MG) & 2.173 .374 & 1.092 .307 & 266.020 & 17.698 & 795.520 & 1.787 \\
\hline $\begin{array}{l}\text { Triângulo Mineiro/Alto } \\
\text { Paranaíba (MG) }\end{array}$ & 2.144 .482 & 1.233 .292 & 163.399 & 22.037 & 723.472 & 2.277 \\
\hline Vale do Rio Doce (MG) & 1.620 .993 & 554.085 & 137.089 & 16.656 & 910.466 & 2.338 \\
\hline Norte de Minas (MG) & 1.610 .413 & 427.048 & 135.268 & 14.993 & 1.023 .524 & 9.571 \\
\hline Oeste de Minas (MG) & 955.030 & 562.720 & 72.610 & 7.872 & 310.915 & 912 \\
\hline Jequitinhonha (MG) & 699.413 & 168.550 & 55.492 & 5.366 & 469.265 & 728 \\
\hline $\begin{array}{c}\text { Campo das Vertentes } \\
\text { (MG) }\end{array}$ & 554.354 & 314.322 & 49.626 & 4.697 & 185.308 & 400 \\
\hline Central Mineira (MG) & 412.712 & 168.221 & 31.937 & 3.102 & 209.098 & 353 \\
\hline Vale do Mucuri (MG) & 385.413 & 92.646 & 37.485 & 4.079 & 249.266 & 1.926 \\
\hline Noroeste de Minas (MG) & 366.418 & 120.173 & 36.262 & 6.158 & 203.421 & 384 \\
\hline
\end{tabular}

Fonte: IBGE, 2010.

Org.: Os Autores, 2021. 
O gráfico 01 abaixo apresenta a distribuição da população da Mesorregião por cor e raça demonstrando que grande parte tem representação por pardos com um total de $64 \%$ da população total e pretos com $8 \%$ da população total, destacando que mais da metade da população da região é negra.

Gráfico 01 - Distribuição da população norte mineira por cor ou raça.

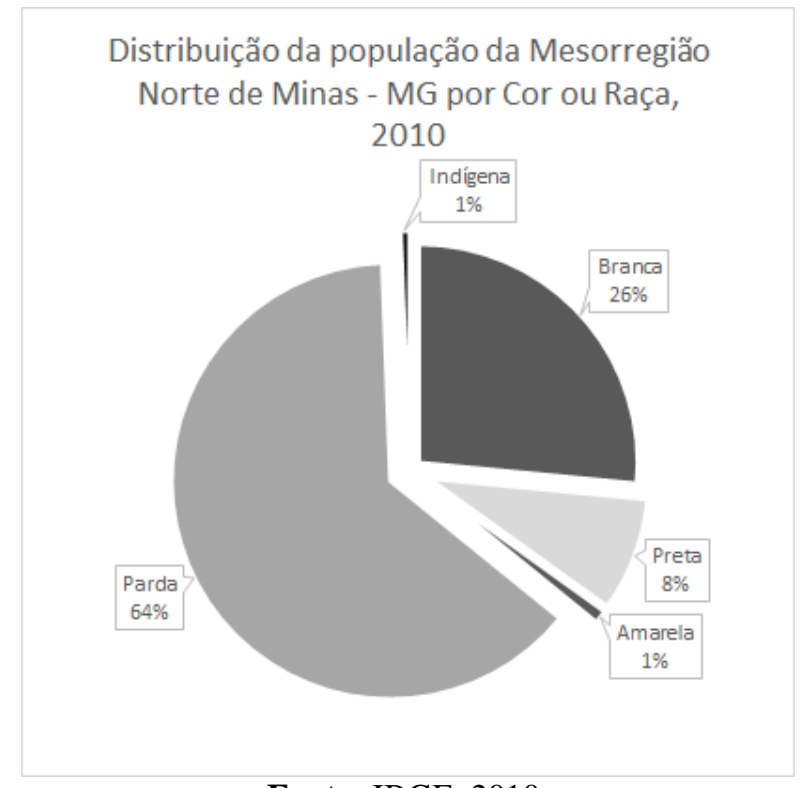

Fonte: IBGE, 2010.

Org.: Os Autores, 2021.

Ao utilizarmos esse recorte traçamos o objetivo de levar a discussão do racismo estrutural e seus impactos na continuidade do ensino em um recorte regional, pois grande parte dos dados são referentes ao recorte nacional, dificultando a análise do assunto de forma mais detalhada sobre as desigualdades raciais, como apresentado na tabela 1, a mesorregião do Norte de Minas, possui a maior população negra do Estado de Minas Gerais.

\section{O NEGRO E O RACISMO: A DESCONTINUIDADE DO ENSINO PARA A POPULAÇÃO NEGRA}

Apesar da similaridade conceitual entre os termos preconceito racial e a discriminação racial, que partem da noção de raça, Almeida (2019) elucida que o preconceito racial baseia- se em formar a noção de um determinado grupo ao ser esse discriminatório ou não, preestabelecida por estereótipos baseados em características raciais. Enquanto, a discriminação racial é ação efetiva de tratar diferenciadamente um membro de determinado grupo racialmente identificado (ALMEIDA, 2019). 
Levando em consideração essas duas ideias pontuadas por Almeida (2019) temos que levar adiante o racismo, que se baseia na forma sistemática de discriminação ao ter como fundo a percepção de raça, ao manifestar-se por meio de práticas conscientes ou inconscientes que resultam em desvantagens ou privilégios para um indivíduo, dependendo do grupo racial a qual ele pertence.

Para seguir a discussão sobre racismos, no viés científico, se faz necessário a compreensão dos termos da instituição e estrutura vindos dos estudos da sociologia. Nesse sentido, Berger e Berger (1977), em linhas gerais, estabeleceram que a instituição é uma organização de pessoas que se dá de forma objetiva, assim a instituição social é colocada como um padrão de controle, que impõe socialmente uma conduta. Sendo assim, é necessário destacar que a instituição social está conectada às entidades sociais, reconhecidas e reguladas por lei.

Ao pensar na estrutura social, Firth (1972) elucidou que corresponde às relações dinâmicas, que possuem determinados níveis de complexidade, sendo essas constantes. Assim, podemos afirmar que a estrutura social seria a forma como a sociedade se organiza em meio a funções, status, papéis sociais e sua compreensão, na sociologia, serve para estudar como os homens se comportam socialmente.

Com o entendimento dos termos instituição e estrutura social podemos seguir a discussão sobre as três concepções de Almeida (2019) acerca do racismo, sendo elas: individualista, institucional e estrutural. O racismo visto como patologia ou anormalidade, denominado nessas concepções, como: racismo individualista, perpassa a compreensão de um fenômeno individual ou coletivo atribuído a um grupo isolado. Essa ação individual seria, então, combatida no campo jurídico por meio de sanções civis. Dessa forma, não se entende a ação como algo vindo de uma sociedade racista ou uma instituição, mas, sim, de um indivíduo racista de um grupo isolado. $\mathrm{O}$ autor supracitado destaca que essa visão é limitada, pois quando colocamos o racismo apenas como algo comportamental negligenciamos que por um longo período histórico essas ações foram legalizadas e apoiadas por líderes políticos e religiosos.

No viés institucional, o racismo não se limita a comportamentos individuais e sim, a ação resultante do funcionamento de uma instituição, que indiretamente proporciona desvantagens e privilégios com base em critérios raciais. Dentro desse contexto podemos notar que o racismo toma proporções políticas e econômicas. Essas baseadas no interesse do grupo que assume essa instituição e utiliza de mecanismos 
institucionais para manter sua hegemonia no poder. Dessa maneira, a cultura, padrões estéticos e práticas de poderes desses grupos torna-se o modelo a ser alcançado na sociedade (ALMEIDA, 2019).

Ao abordar a realidade do racismo institucional, no Brasil, Pace e Lima (2011), explanaram que mesmo após a abolição da escravatura, no dia 13 de maio de 1888, os negros permaneceram a margem da sociedade, não somente da classe dominante branca e latifundiária, mas também do Estado, que, por sua vez, decidiu incentivar a imigração dos europeus, deixando de investir na qualificação e educação da mão de obra dos afro-brasileiros.

Assim, as instituições brasileiras manteriam os padrões das classes dominantes onde os líderes eram homens brancos. Simultaneamente, haviam as políticas de branqueamento junto ao despreparo do negro para competir no mercado de trabalho. Isso fez com que esse grupo se mantivesse na condição de pobreza. Pace e Lima (2011) evidenciaram que, na educação, a distribuição de renda desigual impactou diretamente no acesso e permanência da população negra no ensino básico por um longo período, perpetuando a condição de dominado diante das classes dominantes.

$\mathrm{Na}$ atualidade, a televisão é um dos principais meios de comunicação popular ${ }^{3}$, o perfil do homem branco foi imposto como padrão de beleza, inteligência e superioridade para a ancora do jornalismo que eram majoritariamente brancos e nas telenovelas o ator branco estava sempre representado como alguém de classe dominante, enquanto o negro era interpretado por ações e comportamentos estereotipados relacionados a ações vulgares, pobreza e ilegalidade.

Temos as empresas televisivas que exercem um papel de extrema importância na manutenção da imagem do racismo institucional, seja pelo jornalismo policial apelativo que reforça os estereótipos e a relação da pobreza com criminalidade ou pelas novelas e programas relacionados ao padrão de beleza aceito a seu tempo. Com isso, dissemina, de novo, o padrão estético europeu ao colocá-lo como esplendoroso. Dessa forma, quando se reproduz esses estereótipos a sociedade absorve essa informação e normaliza a condição de dominado em relação aos grupos racionalizados.

Por fim, temos a concepção estrutural do racismo, que serve de complemento para sua interpretação completa, o racismo institucional abordado, anteriormente, é

\footnotetext{
${ }^{3}$ Em pesquisa realizada pelo Instituto Brasileiro de Geografia e Estatística por meio da Pesquisa Nacional por Amostra de Domicílios Contínua - PNAD, realizada em 2018, os dados apontam que dos 71738 mil domicílios particulares permanentes do País onde foram coletadas as amostras, em 96,4\% havia televisão. 
compreendido não apenas como o estabelecimento e manutenção de desvantagem e privilégio baseado em raça. Desse modo, se entende como se estruturou a sua condição de instituição racista, assim a instituição racista seria resultante da sociedade racista.

Dessa forma, a instituição não é quem cria a condição de racismo, ela apenas reproduz o racismo que faz parte de sua estrutura social. Sobre a normalização do racismo Almeida (2019), destacou que:

O fato de parte expressiva da sociedade considerar ofensas raciais como 'piadas', como parte de um suposto espírito irreverente que grassa na cultura popular em virtude da democracia racial, é o tipo de argumento necessário para que o judiciário e o sistema de justiça em geral resistam em reconhecer casos de racismo, e que se considerem racionalmente neutros (ALMEIDA, 2019, p. 59).

Assim, compreender as características de formação do racismo estrutural tornase o único meio de combater institucionalmente as práticas que se tem como normais sob o olhar da sociedade que acredita no mito da democracia racial e da meritocracia. Neste sentido, Almeida (2019) explicou que diante as condições estruturais é válido questioná-las, pois nosso contexto estrutural configura-se com o domínio das classes dominantes que agiram historicamente de maneira que limitou as possibilidades de ação dos sujeitos racionalizados na sociedade. E, “[...] em um país desigual como o Brasil, a meritocracia avaliza a desigualdade, a miséria e a violência, pois dificulta a tomada de posições políticas efetivas contra a discriminação racial, especialmente por parte do poder estatal" (ALMEIDA, 2019, p.63).

Podemos então entender o racismo estrutural como a manutenção de ações racistas cotidianas que tornam normais a inferioridade, agressões policiais, baixo indicie educacional entre outras diversas mazelas sofridas pela população negra como algo que faz parte da ordem social dessa sociedade atual.

E, desta maneira, Almeida (2019) apontou que o uso do termo "estrutura" não inutiliza as ações e políticas antirracistas, nem àqueles que cometem os atos racistas, porque não tem parcela de culpa sobre suas ações discriminatórias. Diante disso, temos o racismo como processo histórico e político que resulta diretamente ou indiretamente em condições desvantajosas e ações discriminatórias contra grupos racialmente identificados. Dentre as formas de perpetuar a condição de superioridade do branco, temos o exemplo das escolas. 
Nesse sentido, Almeida explana que “[...] a escola reforça todas as percepções ao apresentar um mundo em que negros e negras não têm muitas contribuições importantes para a história, literatura, ciência e afins, resumindo-se a comemorar a própria libertação graças à bondade de brancos conscientes" (2019, p. 65). Essa citação reflete nosso passado histórico, onde não valorizamos ou sequer citamos a contribuição dos negros para nossa cultura e história, à medida que não deu destaque aos seus movimentos. As lutas e as reivindicações foram de extrema importância para a conquista de leis voltadas a educação, e a criminalização do racismo, ou até mesmo quando pensamos apenas na Revolução Francesa e não debruçamos acerca da Revolução Haitiana não se entender que a revolução negra foi fundamental para a reivindicação de direitos escravos, no Brasil, como citado anteriormente.

Somando a imagem criminosa passada pelos jornais sensacionalistas com a representatividade negada em filmes, novelas e até mesmo nas escolas, temos apenas um espelho para população negra, o criminoso. Assim podemos repensar a ideia de que o crime é uma opção para as populações periféricas que vivem em locais com altos índices de violência. Além da proximidade da criminalidade e violência, quando esses jovens tentam se entreter eles são bombardeados com a visão negativa passada pela mídia.

\section{O RACISMO ESTRUTURAL E O PAPEL DAS ESCOLAS}

Compreendemos que os impactos no acesso à educação foram um dos principais motivos da manutenção da condição de desigualdade racial, no Brasil. De acordo com uma pesquisa realizada, em 2018, pelo Instituto Paulo Montenegro e ação social do Instituto Brasileiro de Opinião Pública e Estatística (IBOPE) denominada como Indicador de Alfabetismo Funcional (INAF) foi demonstrado em um recorte com 3 grupos: pardos, pretos e brancos, que entre os entrevistados os de cútis parda e preta representavam respectivamente $5 \%$ e $8 \%$ daqueles sem nenhuma escolaridade, enquanto os de cútis branca apenas 3\%, e entre aqueles que possuíam apenas o Ensino Fundamental Series Iniciais 16\% eram pardos e 17\% pretos, enquanto os brancos $12 \%$. Esses dados apresentam uma realidade onde o papel da escola se torna fundamental para a quebra do ciclo que envolve o racismo estrutural.

$\mathrm{Na}$ perspectiva regional em uma análise mais aprofundada, especializamos os municípios da Mesorregião do Norte de Minas (MAPA 01) de forma que foram 
evidenciados quais dos municípios possuem as maiores taxas de evasão escolar (MAPA 02).

Mapa 01: Localização e Espacialização dos Municípios do Norte de Minas.

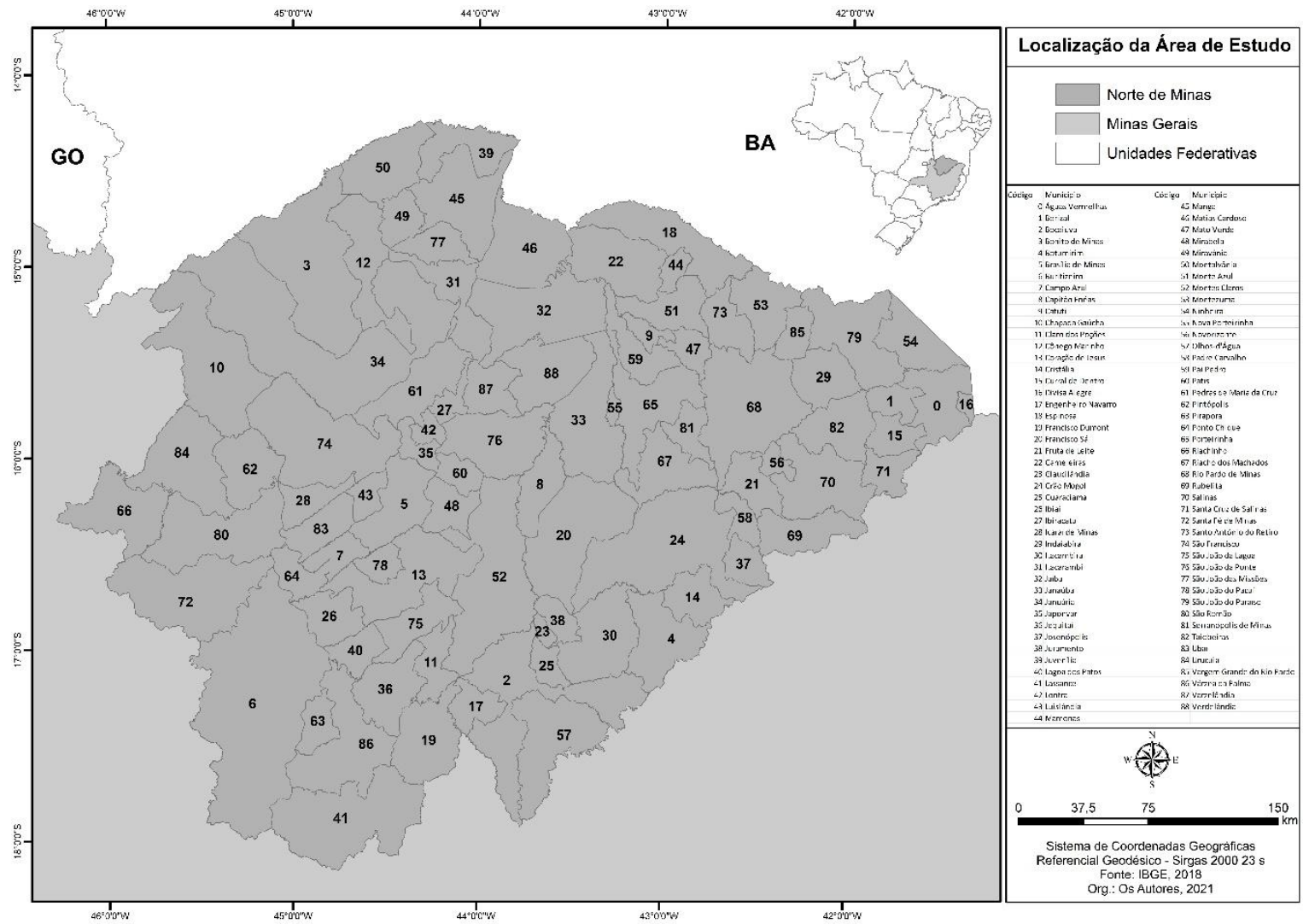

Antes de darmos foco aos municípios de menor e maior taxa de evasão, destacamos em nossa análise o município de Montes Claros que constitui-se como o núcleo urbano de maior dinamismo econômico e infraestrutura da região norte mineira, na atualidade, essa condição se mantém, por meio de sua economia diversificada, que possui, como base primordial: o comércio, a indústria e seu desenvolvimento na área educacional, em que tem um impacto positivo na formação e capacitação de profissionais em diversas áreas do conhecimento. Mediante o seu papel de polo universitário. A população afrodescendente (somando autodeclarados pardos e pretos) é aproximadamente de $66 \%$ da população municipal. (FRANÇA et al., 2009).

Montes Claros se mantém em uma posição mediana conforme a taxa de evasão escolar no ensino Fundamental e Médio (Figura 3). Com uma população de 361.915 pessoas (IBGE, 2010) e uma quantidade de matrículas no ensino fundamental e médio de 49.390 e 15.907 respectivamente (INEP, 2020), calculando uma taxa de $13,65 \%$ e $4,40 \%$ de matriculas em relação a população total. 
02: Taxa de Evasão Escolar - Mesorregião Norte de Minas.

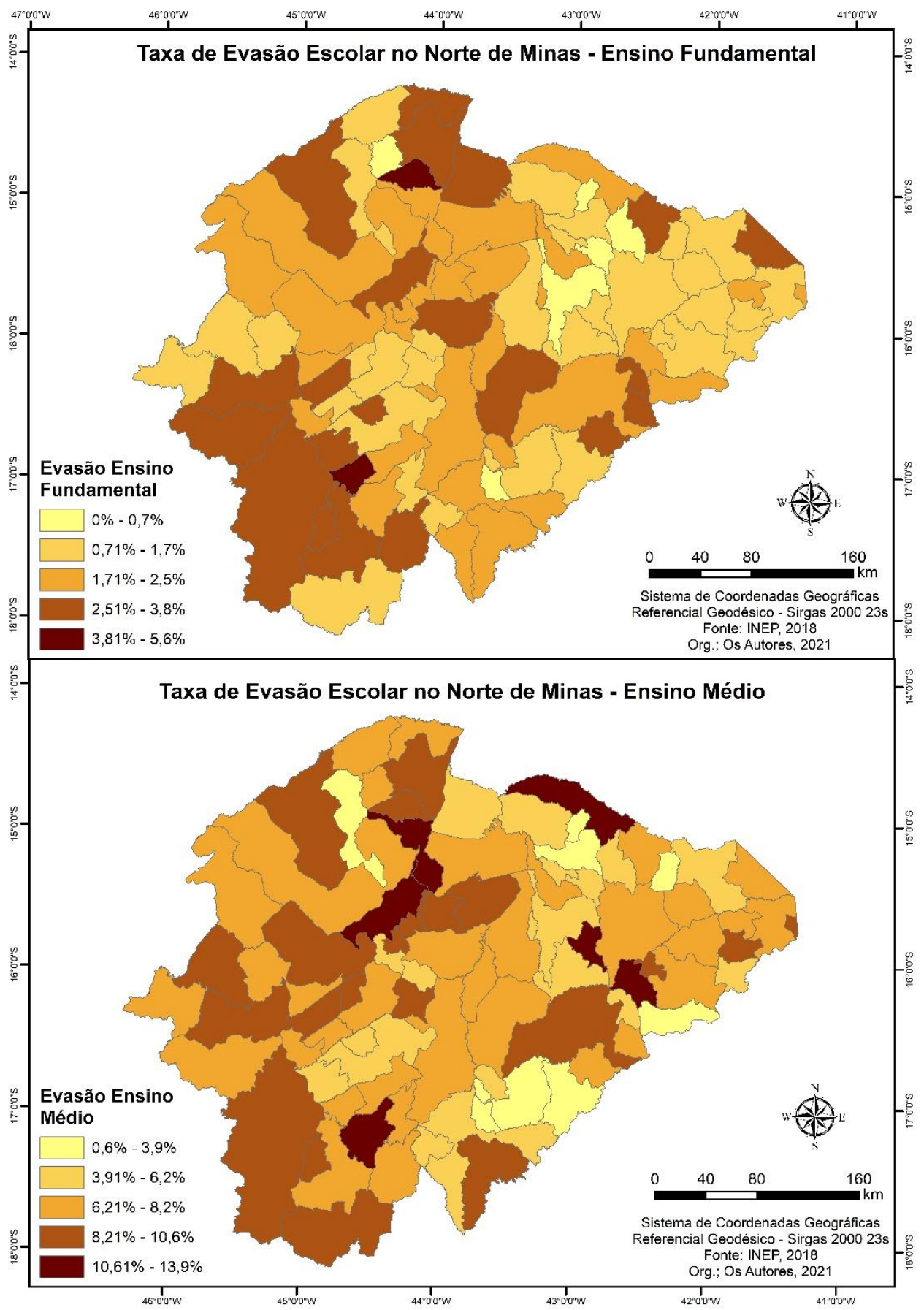

Os Municípios com maior índice de evasão no ensino fundamental $(3,81 \%$ a $5,6 \%$ ) foram São João das Missões e Lagoa dos Patos ${ }^{4}$. Tendo em vista o município de São João das Missões com uma das maiores taxas de evasão do ensino fundamental e uma população de 11.715 habitantes (IBGE, 2010), e de acordo com o INEP (2020),

\footnotetext{
${ }^{4}$ A escolha de análise dos municípios foi feita com base nas classes mais baixas e mais altas com relação a legenda do mapa dos municípios e ainda levando em consideração os municípios com população próxima ou maior do que dez mil habitantes.
} 
houveram 2.644 e 829 matrículas no ensino fundamental e médio o que representa $22,57 \%$ e $7,08 \%$ da população total do município.

Com os menores índices de evasão no ensino fundamental $(0 \%$ a $0,7 \%)$ se destacaram os municípios de Miravânia, Mamonas, Santo Antônio do Retiro, Mato Verde, Porteirinha e Guaraciama.

O município de Porteirinha com uma população de 37.627 habitantes (IBGE, 2010) está entre os municípios com a menor taxa de evasão do Norte de Minas, os números referentes a quantidade de matrículas no ensino fundamental e médio (INEP, 2020) são de 4.605 e 1.404 respectivamente, o que nos leva a verificar que as matrículas representam $12,24 \%$ e $3,73 \%$ da população total do município.

Com relação a menor taxa de evasão o segundo município a ser analisado nessa classe é de Mato Verde, com uma população total de 12.684 (IBGE, 2010), e a quantidade de matrículas no ensino fundamental e médio é de 1.439 e 456 respectivamente o que representa uma taxa de $11,35 \%$ e $3,6 \%$ da população total do município.

Os municípios que apresentaram uma maior taxa de evasão com relação ao ensino médio, foram: Itacarambi, Pedras de Maria da Cruz, Espinosa, Serranópolis de Minas, Fruta de Leite e Jequitaí.

O município de Espinosa com uma das maiores taxas de evasão do ensino médio tem uma população de 31.113 habitantes (IBGE, 2010) e mesmo assim apresenta uma alta taxa de evasão escolar se comparada com outros municípios analisados, de acordo com o INEP (2020), houveram 3.870 e 1.285 matrículas respectivamente no ensino fundamental e médio e em relação a população total estes números representam $12,44 \%$ e $4,13 \%$.

Em sequência o segundo município a ser analisado com maior população dentre os que têm uma maior taxa de evasão escolar no ensino médio é o município de Itacarambi, com 17.720 habitantes (IBGE, 2010), fazendo com que seja observada uma população também mais jovem. A quantidade de matrículas no ensino fundamental e médio é de 2.611 e 688 respectivamente (INEP, 2020), o que nos leva a verificar a representatividade com relação a população total de $14,73 \%$ e 3,88\%.

Os municípios que apresentaram uma menor taxa de evasão com relação ao ensino médio: Cônego Marinho, Mamonas, Monte Azul, Vargem Grande do Rio Pardo, Rubelita, Botumirim, Itacambira, Glaucilândia, Guaraciama. 
Dentre os municípios com uma menor taxa de evasão no ensino médio, temos o destaque para, Monte Azul, com uma população total de 21.994 habitantes (IBGE, 2010), sendo que a quantidade de matrículas no ensino fundamental e médio são de 2.307 e 744 respectivamente (INEP, 2020), o que remete a 10,49\% e 3,38\% da população total do município.

Cônego Marinho ocupa o segundo lugar da análise possuindo uma população muito menor do que a de Monte Azul, entretanto, maior do que as demais selecionadas na classe de municípios com a menor evasão escolar no ensino médio. Tendo uma população total de 7.101 (IBGE, 2010), e o número de matrículas com relação ao ensino fundamental e médio é de 981 e 361 respectivamente (INEP, 2020), é notório que representa um percentual de $13,81 \%$ e $5,08 \%$ da população total.

$\mathrm{Na}$ atualidade, os impactos racismo estrutural resultam em diversas barreias na ascensão do pobre-negro mediante a sua formação educacional e capacitação profissional, perpetuando a manutenção da condição de pobreza desse grupo.

No Brasil, segundo o IBGE (2019) ${ }^{5}$, a população negra representa mais da metade da população geral ao ser $53,92 \%$, mesmo assim, em um estudo feito sobre as Desigualdades Sociais por Cor ou Raça, que foi publicado pelo IBGE, no final de 2018, foi revelado que 68,6\% dos cargos gerenciais, no país, são ocupados por brancos e apenas $29,9 \%$ deles são ocupados por pretos ou pardos. Também relacionado ao mercado de trabalho, o estudo apresentou uma taxa de subutilização de 18,8\% entre brancos, enquanto há $29 \%$ entre pretos e pardos, essa subutilização representa o índice de preterimento do trabalhador no acesso a cargos de trabalho. E, isso ocorre mesmo quando os trabalhadores cumprem os requisitos de capacitação e qualificação exigidos para esses cargos. Além disso, os estudos também apontam que, entre as pessoas que vivem abaixo da linha da pobreza, $15,4 \%$ são brancos e $32,9 \%$ são pretos ou pardos.

E, no âmbito da política, 24,4\% dos deputados federais eleitos, em 2018, se consideram pretos ou pardos, enquanto $75,6 \%$ considera ser branco. E, por fim, nos levantamentos de índices de violência, a taxa de homicídio foi representada por $34 \mathrm{em}$ cada cem mil, entre pessoas brancas, e de 98 em cada cem mil, entre pretos e pardos. Mostrando que mesmo sendo mais da metade da população brasileira os negros são os que mais sofrem com a violência e os que menos tem representação política para levar

\footnotetext{
5 Disponível em: https://educa.ibge.gov.br/jovens/conheca-o-brasil/populacao/18319-cor-ouraca.html\#: :text=De\%20acordo\%20com\%20ou\%20ind\%C3\%ADgenas. Acesso em: 13 jun. de 2021.
} 
mudanças a essas diversas situações vindas de uma construção social e política que os colocou em situações vulneráveis por anos, consequentemente, sem prestigio social (IBGE, 2018).

Nesse sentido, temos o negro que não se sente bem visto, representado, protegido ou respeitado, vive em uma sociedade que desde o início de sua independência e formação de sua constituição o coloca a margem do desenvolvimento intelectual e econômico do país vive seu dilema de conseguir um emprego para se manter ou arriscar uma educação superior sem saber se será promissor em sua formação acadêmica ou técnica.

A questão da qualidade educacional brasileira é um desafio no cenário de políticas públicas é um tema que sempre será destaque nos debates sobre educação, ao analisar diversos indicadores educacionais brasileiros produzidos por órgãos oficiais, diversas questões ganharam força, dentre elas a questão da permanência.

Na relação ao acesso à educação, a taxa de analfabetismo dos brancos é de $3,9 \%$, e dos pretos e pardos é de $9,1 \%$. Em relação à distribuição das taxas de matrícula no ensino superior, se constata que, na rede pública, os alunos brancos representavam $49,7 \%$ e os pretos ou pardos 50,3\%. Na rede privada, 53,4\% dos alunos são brancos e 46,6\% dos alunos são pretos ou pardos. Sendo assim, se percebe que existe uma relativa melhoria na inserção do negro ao ensino superior, mas se revela como fato extremamente recente, quando correlaciona as porcentagens verifica-se que tem maior taxa de analfabetismo por parte da população negra (IBGE, 2019).

Dados do IBGE (2019), em relatório da Pesquisa Nacional por Amostra de Domicílios (PNAD), de 2019, mostraram que apesar do aumento de pretos e pardos no ensino superior, em relação a porcentagem de pessoas entre 14 e 29 anos que não frequentam a escola com nível inferior ao ensino médio os pardos e pretos representam $71,7 \%$ enquanto os brancos representam $27,3 \%$ e dentre os maiores motivos da população preta e parda abandonar os estudos estão: necessidade de trabalhar com 38,7 $\%$, falta de interesse em estudar $29,1 \%$, por gravidez $10,5 \%$.

No Brasil de acordo com dados de 2019 do Sistema de Informações sobre Nascidos Vivos (SINASC), relativos aos dados de gravidez no grupo de mulheres na faixa etária 10 a 14 anos de idade em que se soma a quantidade de nascimentos entre pretos e pardos chegamos a 75,73\% em comparação com mulheres brancas que representam apenas $17,07 \%$. Já entre mulheres de 15 a 19 anos de idade os números 
chegam a $72,66 \%$ na soma de mulheres pretas e pardas em comparação com $22,87 \%$ de nascimentos entre mulheres brancas.

Dados estes que apontam juntamente com os motivos de abandono por gravidez que as adolescentes negras são as que nesse contexto mais sofrem com as consequências da gravidez precoce durante a etapa escolar.

\section{CONSIDERAÇÕES FINAIS}

O racismo estrutural está arraigado nas vísceras da sociedade compreender as características de sua formação torna-se o único meio de combatê-lo institucionalmente as práticas que se tem como normais sob o olhar da sociedade que acredita no mito da democracia racial e da meritocracia por meio de políticas públicas de assistência social e similares.

Não tão pouco o racismo estrutural tem a sua carga negativa sobre o ambiente escolar, afetando os mais diversos jovens na situação analisada anteriormente, temos ainda, problemas relacionados à violência, que por meio, do racismo estrutural, acaba sendo despejado nesta mesma parcela estudantil.

A realidade do abandono se destaca principalmente pela falta de interesse dos alunos em continuar no processo de estudos e pode ser baseado na falta de perspectiva acadêmica e profissional, além das desigualdades socioeconômicas que forçam o jovem negro a buscar o emprego no mesmo período que o enfoque principal deveria ser a educação, e por fim, a gravidez precoce das adolescentes negras demonstram mais uma falha em nosso sistema educacional, pela falta de recursos e capacitação de profissionais focados na educação sexual e social.

Apresentar a perspectiva do racismo estrutural em um recorte regional é algo extremamente necessário, afim de esclarecer a realidade dos mais diversos grupos sociais de forma detalhada, mas esta tarefa se torna cada vez mais complicada, visto que, órgãos competentes, como o IBGE e INEP não recebem o devido investimento necessário para a continuidade das pesquisas de qualidade. Temos como exemplo o atraso do Censo 2020, sendo um dos principais empecilhos para a aquisição de dados mais atuais para um melhor aproveitamento da pesquisa.

\section{REFERÊNCIAS}

ALMEIDA, Silvio. Racismo estrutural. São Paulo: Editora Pólen Livros, 2019. 
BERGER, Peter. BERGER, Brigitte. O que é uma instituição social. Sociologia e sociedade: leituras de introdução à sociologia. Rio de Janeiro: LTC, 1977.

BBC. Caso George Floyd: morte de homem negro filmado com policial branco com joelhos em seu pescoço causa indignação nos EUA. BBC News, Rio de Janeiro, 5 de mai. 2020. Disponível em: https://g1.globo.com/mundo/noticia/2020/05/27/casogeorge-floyd-morte-de- homem-ne eua.ghtml. Acesso em: 20 nov. de 2020.

. Constituição da República Federativa do Brasil de 1988. Diário Oficial da

União, Brasília, 5 out. 1988. Disponível em: http://www.planalto.gov.br/ccivil_03//constituicao.htm. Acesso em: 10 mar. 2020.

Instituto Brasileiro de Geografia e Estatística. Desigualdades sociais por cor ou raça no Brasil. Brasília, 2019.

Pretos ou pardos estão mais escolarizados, mas desigualdade em relação aos brancos permanece. Agência IBGE Notícias, 2019. Disponível em: https://agencia denoticias.ibge.gov.br/agencia-sala-de-imprensa/2013-agencia-denoticias/releases/25989-aldade-em-relacao-aos-brancos. Acesso em: 20 dez. 2019.

CNN. Histórias de crianças baleadas no Rio de Janeiro ganham destaque em protesto. CNN Brasil, Rio de Janeiro, 4 de jul. 2020. Disponível em: https://www.cnnbrasil.com.br/nacional/2020/07/04/historias-de-criancas-baleadasno-rio-de- janeiro-ganham-destaque-em-protesto. Acesso em: 20 nov. de 2020.

DEMOGRÁFICO, IBGE. Censo. 2010. Disponível em: https://censo2010.ibge.gov.br. Acesso em: 20 de julho, 2021.

EMICIDA. Emicida - AmarElo (álbum completo). YouTube, 2019. Disponível em https://www.youtube.com/playlist?list=PLL1gm0aLlr0H. Acesso em: 19 jun. 2020.

FIRTH, Raymond. Organização social e estrutura social. Homem e sociedade. São Paulo: Nacional, 1972.

FRANÇA, Iara Soares de; PEREIRA, Anete Maria; SOARES, Beatriz. Cidade média, polarização regional e setor de educação superior: estudo de Montes Claros, no norte de Minas Gerais. In. Formação (Presidente Prudente), v. 02, p. 52-69, 2009.

GUIMARÃES, Antônio Sérgio Alfredo. Depois da democracia racial. In. Tempo social, v. 18, n. 2, p. 269-287, 2006.

LIMA, Ana; CATELLI Jr., Roberto. INAF Brasil 2018: resultados preliminares. São Paulo: Ação Educativa \& Ação Social do IBOPE, 2018.

Matrículas no ensino fundamental: INSTITUTO NACIONAL DE ESTUDOS E PESQUISAS EDUCACIONAIS ANÍSIO TEIXEIRA. Sinopse Estatística da Educação Básica 2020. Brasília: Inep, 2021. Disponível em <http://portal.inep.gov.br/sinopses-estatisticas-da-educacao-basica>. Acesso em: 25.06.2021. 
Matrículas no ensino médio: INSTITUTO NACIONAL DE ESTUDOS E PESQUISAS EDUCACIONAIS ANÍSIO TEIXEIRA. Sinopse Estatística da Educação Básica 2020. Brasília: Inep, 2021. Disponível em $<$ http://portal.inep.gov.br/sinopses-estatisticas-da-educacao-basica>. Acesso em: 25.06.2021.

MINTZ, Sidney e PRICE, Richard. O nascimento da cultura afro-americana: uma perspectiva antropológica. Rio de Janeiro: Editora Pallas, 2003.

PACE, Ângela F.; LIMA, Marluce O. Racismo Institucional: apontamentos iniciais. In. Revista do Difere, v. 1, n. 2, p. 1-17, 2011.

ROLLEMBERG, Denise; QUADRAT, Samantha Viz. A construção social dos regimes autoritários: legitimidade, consenso e consentimento no século XX. Brasil e América Latina. v. 2. In: A construção social dos regimes autoritários: legitimidade, consenso e consentimento no século XX. Brasil e América Latina. v. 2. 2010. p. 642682.

SERRANO, Pedro Estevam Alves Pinto. Autoritarismo e golpes na América Latina: breve ensaio sobre jurisdição e exceção. Alameda Casa Editorial, 2016. 